\title{
Organoaxial Gastric Volvulus-Chronic Hematoma and a Gastric Twist
}

\author{
Sivaram Sridharan*, Govindarajalu Muthukumaran, Arcot Rekha, Touzeen Hussain \\ Department of General Surgery, Saveetha Medical College Hospital, Tamil Nadu, India \\ Email: *shiv316@gmail.com
}

How to cite this paper: Sridharan, S., Muthukumaran, G., Bekha, A. and Hussain, T. (2019) Organoaxial Gastric Volvulus-Chronic Hematoma and a Gastric Twist. Case Reports in Clinical Medicine, 8 , 152-156.

https://doi.org/10.4236/crcm.2019.86018

Received: May 8, 2019

Accepted: June 21, 2019

Published: June 24, 2019

Copyright $\odot 2019$ by author(s) and Scientific Research Publishing Inc. This work is licensed under the Creative Commons Attribution International License (CC BY 4.0).

http://creativecommons.org/licenses/by/4.0/

\begin{abstract}
A 70-year-old male presented with gastric volvulus secondary to a hematoma that caused an organoaxial rotation. Contrast-enhanced CT was contributory to the diagnosis. The patient underwent laparotomy with gastrojejunostomy and jejunojejunostomy. We present our findings and review the literature of this uncommon pathology. A written informed consent was obtained from the patient for publication of this case.
\end{abstract}

\section{Keywords}

Organoaxial, Gastric, Volvulus, Chronic, Hematoma

\section{Introduction}

Gastric volvulus is a rare entity which can be difficult to diagnose. Gastric volvulus is defined as a twist or an abnormal rotation of the stomach of over 180 degrees. The presentation can be acute where the volvulus results in a closed loop foregut obstruction [1], compromises the blood supply to the affected segment and is a surgical emergency. In some patients, the symptoms are non-specific and will present with an intermittent dull aching abdominal pain, nausea and loss of weight because of poor oral intake. Gastric volvulus is classified into primary and secondary types. Primary gastric volvulus occurs as a result of laxity in the ligaments that anchor the stomach to the surrounding organs and secondary gastric volvulus is due to a pathology elsewhere. More specifically, the volvulus is either organoaxial or mesenteroaxial; the former is more common and leads to disastrous complications if left undiagnosed. X-ray can raise a high index of suspicion, but a computed tomographic scan of the abdomen will confirm the diagnosis. The aim of the surgery is to decompress the stomach and prevent re-rotation of the stomach. Medical and endoscopic man- 
agement is primarily advised to older patients who are not fit for surgery. Surgical or laparoscopic intervention is the treatment of choice in patients presenting with signs of acute gastrointestinal bleeding.

\section{Case Presentation}

A 70-year-old patient came to the emergency room with complaints of upper abdominal dull aching pain, fullness and dyspepsia for 3 days duration. He gave history of loss of weight for the last 3 months. He gave an alleged past history of blunt abdominal trauma for which he was conservatively treated in a local hospital. On clinical examination, the epigastric region was grossly distended, yet a nasogastric tube could not be inserted. UGI scopy showed a distorted stomach with stasis of fluid. Contrast-enhanced CT abdomen (Figure 1(a) and Figure 1(b)) showed a grossly distended stomach that was abnormally oriented; the fundus was situated anteroinferiorly and the pylorus was situated superior and anterior to the gastro-esophageal junction, consistent with gastric volvulus.

At laparotomy, pancreas was visualised through a rent in the greater omentum (Figure 2). The omentum was adherent to an organized hematoma at the

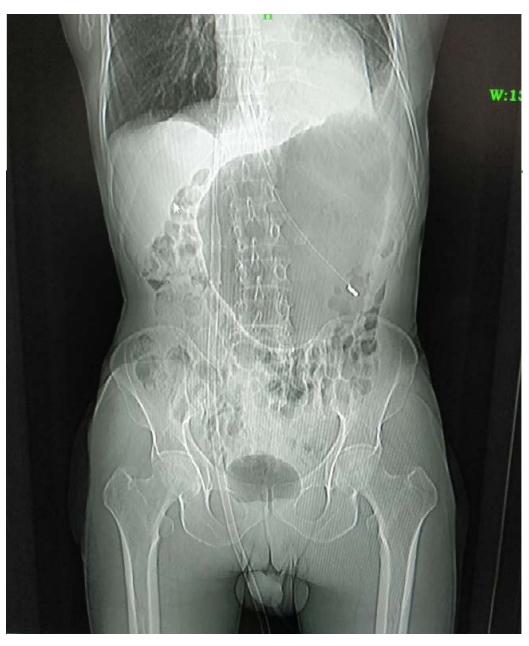

(a)

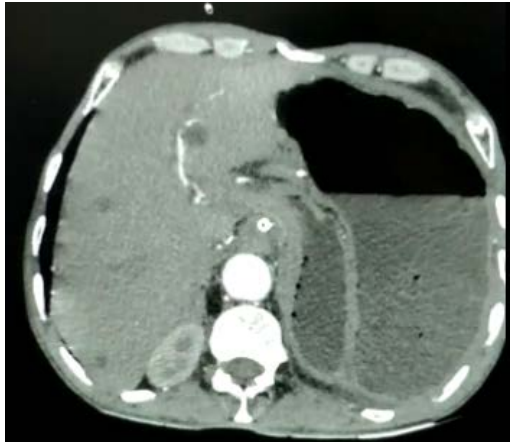

(b)

Figure 1. Shows the dilated and abnormally oriented stomach.

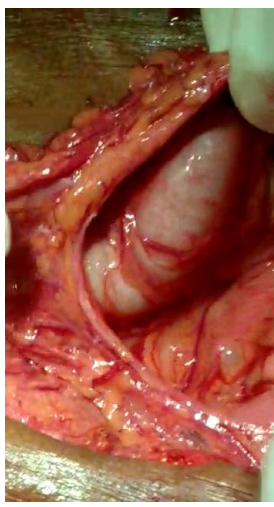

Figure 2. Shows the rent in the omentum and the dilated stomach. 
OG junction, and this had caused an organoaxial volvulus. The volvulus was derotated, malignancy excluded and an anterior gastrojejunostomy with jejunojejunostomy was performed. The post operative period was uneventful and at 2 months follow up, the patient had gained $1 \mathrm{~kg}$ weight and the endoscopy was normal (stoma was healthy, the afferent and efferent loops functioning well)

\section{Discussion}

Gastric volvulus occurs in $10 \%-20 \%$ of children less than 1 year of age and is uncommon in adults [2]. The classical triad was described by Bouchardt in 1904 [3]. Primary gastric volvulus occurs due to the laxity, disruption or elongation in the ligamentous structures attached to the stomach; the gastrohepatic, gastrocolic, gastrolienal and gastrophrenic ligaments [4]. Secondary gastric volvulus is due to a defect in the gastric anatomy or due to defects in the adjacent structures, neuromuscular diseases (motor neuron disease [5], poliomyelitis [6]), intra-abdominal tumours and factors that cause diaphragmatic elevation (such as phrenic nerve palsy [7], left lung resection [8]). Gastric volvulus can be organoaxial (59\%) [9] and mesenteroaxial rotation (more common in children). The risk of strangulation in an organoaxial rotation is between $5 \%-28 \%$ and is low in mesteroaxial rotation [10].

$70 \%$ of the patients with acute organoaxial volvulus present by Bouchardt's triad; epigastric discomfort, retching and the inability to pass a nasogastric tube [11]. The close proximity of the cardia and the fundus of the stomach to the lower esophageal sphincter and the 180 degree turn along the two fixed points of the stomach (cardia and pylorus) are the reasons why difficulty is encountered when inserting the nasogastric tube. Chronic gastric volvulus presents with vague, dull aching, intermittent abdominal pain, early satiety, dyspepsia, loss of weight and loss of appetite [4]. Hiccups is a subtle sign of gastric volvulus [12]. Hematemesis occurs after mucosal ischaemia and sloughing.

A plain erect abdominal $\mathrm{x}$-ray film demonstrates a spherical stomach with double air fluid levels. Albas et al. described 4 radiological findings predictive for a gastric volvulus at contrast imaging; namely, gastric air fluid level above the diaphragm, a paucity of distal bowel gas, a reversal of the relative position of the greater curvature of the stomach and a downward pointing pylorus [13].

After resuscitation and medical optimization, the aim of the surgery is to decompress and de-rotate the volvulus and fix the stomach to prevent recurrence. The gastropexy can be approached laparoscopically also. Morelli et al. anchored the stomach to the anterior abdominal wall by placing 4 sutures on the greater and lesser curvature of the stomach near the fundus and the body [14]. Palanivelu et al. performed laparoscopic suture gastropexy in 14 patients (10 chronic volvulus and 4 acute). Majority of patients presented with a secondary gastric volvulus. All 14 patients did not develop complication post operatively [15]. In older patients who are unfit for surgery, endoscopic gastrostomy (PEG) showed good results [16]. Combined laparoscopic and endoscopic management of 
the volvulus is reported. In cases of secondary gastric volvulus, the paraesophageal hernia must be repaired. Robotic repairs of parahiatal hernia with a mesh offer a tension free primary closure of the defect [17].

\section{Conclusion}

Gastric volvulus is rare, has a non-characteristic presentation and results in strangulation if undetected. A high index of suspicion is needed for a clinical diagnosis. The imaging findings are characteristic and confirm the diagnosis. Laparoscopic/open derotation and pexy offer good results for this uncommon condition.

\section{Conflicts of Interest}

The authors declare no conflicts of interest regarding the publication of this paper.

\section{References}

[1] Tanner, N.C. (1968) Chronic and Recurrent Volvulus of the Stomach with Late Results of "Colonic Displacement". The American Journal of Surgery, 115, 505-515. https://doi.org/10.1016/0002-9610(68)90194-3

[2] Godshall, D., Mossallam, U. and Rosenbaum, R. (1999) Gastric Volvulus: Case Report and Review of the Literature. The Journal of Emergency Medicine, 17, 837-840. https://doi.org/10.1016/S0736-4679(99)00092-X

[3] Borchardt, M. (1904) Aus Pathologie und therapie des magen volvulus. Arch Klin Chir, 74, 243-260.

[4] Rashid, F., Thangarajah, T., Mulvey, D., Larvin, M. and Iftikhar, S.Y. (2010) A Review Article on Gastric Volvulus: A Challenge to Diagnosis and Management. International Journal of Surgery, 8, 18-24. https://doi.org/10.1016/j.ijsu.2009.11.002

[5] Lowenthal, M.N., Odes, H.S. and Fritsch, E. (1985) Endoscopic Reduction of Acute Gastric Volvulus Complicating Motor Neuron Disease. Israel Journal of Medical Sciences, 21, 552-553.

[6] Kumar, A., Chaudhary, D., Agarwal, K.N. and Bhargava, V. (1995) Chronic Gastric Volvulus-An Unusual Complication of Poliomyelitis. Indian Pediatrics, 32, 502-504.

[7] Sevcik, W.E. and Steiner, I.P. (1999) Acute Gastric Volvulus: Case Report and Review of the Literature. Canadian Journal of Emergency Medicine, 1, 200-203. https://doi.org/10.1017/S1481803500004206

[8] Farber, B.A., Lim, I.I.P., Murphy, J.M., Price, A.P., Abramson, S.J. and La Quaglia, M.P. (2015) Gastric Volvulus Following Left Pneumonectomy in an Adolescent Patient. Journal of Pediatric Surgery Case Reports, 3, 447-450. https://doi.org/10.1016/j.epsc.2015.08.014

[9] Milne, L.W., Hunter, J.J., Anshus, J.S. and Rosen, P. (1994) Gastric Volvulus: Two Cases and a Review of the Literature. The Journal of Emergency Medicine, 12, 299-306. https://doi.org/10.1016/0736-4679(94)90270-4

[10] Carter, R., Brewer, L.A. Hinshaw, D.B. (1980) Acute Gastric Volvulus: A study of 25 cases. The American Journal of Surgery, 140, 99-106. 
https://doi.org/10.1016/0002-9610(80)90424-9

[11] Chau, B. and Dufel, S. (2007) Gastric Volvulus. Emergency Medicine Journal, 24, 446-447. https://doi.org/10.1136/emj.2006.041947

[12] McElreath, D.P., Olden, K.W. and Aduli, F. (2008) Hiccups: A Subtle Sign in the Clinical Diagnosis of Gastric Volvulus and a Review of the Literature. Digestive Diseases and Sciences, 53, 3033-3036. https://doi.org/10.1007/s10620-008-0258-2

[13] Lopez, P.P. and Megha, R. (2019) Gastric Volvulus. StatPearls, Treasure Island, FL.

[14] Umberto Morelli, Maurizio Bravetti, Paolo Ronca, Roberto Cirocchi, Angelo De Sol, Alessandro Spizzirri, Giammario Giustozzi and Francesco Sciannameo. (2008) Laparoscopic Anterior Gastropexy for Chronic Recurrent Gastric Volvulus: A Case Report. Journal of Medical Case Reports, 2, 244.

https://doi.org/10.1186/1752-1947-2-244

[15] Palanivelu, C., Rangarajan, M., Shetty, A.R., Senthilkumar, R. (2007) Laparoscopic Suture Gastropexy for Gastric Volvulus: A Report of 14 Cases. Surgical Endoscopy, 21, 863-866. https://doi.org/10.1007/s00464-006-9089-4

[16] Baudet, J.S., Armengol-Miro, J.R., Medina, C., Accarino, A.M., Vilaseca, J. and Malagelada, J.R. (1997) Percutaneous Endoscopic Gastrostomy as a Treatment for Chronic Gastric Volvulus. Endoscopy, 29, 147-148. https://doi.org/10.1055/s-2007-1004106

[17] Jindal, S., Hukkeri, V.S., Qaleem, M., Tandon, V. and Govil, D. (2016) Robotic Repair of a Parahiatal Hernia with Gastric Volvulus. Apollo Medicine, 13, 235-238. https://doi.org/10.1016/j.apme.2016.08.004 